$8-2020$

Prevalence of allergic rhinitis among healthcare workers and its impact on their work: A cross-sectional survey at a tertiary healthcare centre in Pakistan

Moghira Iqbaluddin Siddiqui

Rahim Dhanani

Huzaifa Moiz

Follow this and additional works at: https://ecommons.aku.edu/ pakistan_fhs_mc_surg_otolaryngol_head_neck

Part of the Allergy and Immunology Commons, Otolaryngology Commons, and the Otorhinolaryngologic Diseases Commons 


\section{Prevalence of allergic rhinitis among healthcare workers and its impact on their work: a cross-sectional survey at a tertiary healthcare centre in Pakistan}

Moghira Iqbaluddin Siddiqui, Rahim Dhanani, Huzaifa Moiz

\begin{abstract}
A study was conducted to determine the frequency of allergic rhinitis among healthcare professionals and its impact on their work at the Aga Khan University Hospital Karachi Pakistan. Healthcare workers including doctors, nurses, technicians and pharmacists were included. Participants were asked to fill a questionnaire consisting of score for allergic rhinitis (SFAR), and work productivity and activity impairment questionnaires. Out of 167 workers, 101 were males. Mean age of the participants was $29.0 \pm 5.9$ years. Overall prevalence of allergic rhinitis among healthcare workers was found to be frequency (19.2\%). We noted that 13 individuals reported to have missed their work in the past week accounting to $4.3 \%$ of their work. When calculated with the actual work hours $35.9 \%$ of their work was reported to have been impaired due to this condition.
\end{abstract}

Keywords: Allergic rhinitis, Work productivity, Prevalence. https://doi.org/10.5455/JPMA.17588

\section{Introduction}

Allergic rhinitis is a common condition which is defined as an lgE mediated inflammatory reaction of the nasal mucosa caused by allergen. ${ }^{1}$ Common clinical findings include recurrent sneezing, rhinorrhoea, nasal congestion, nasal itching and itchy eyes. These symptoms are bothersome and may cause disturbed sleep, daytime somnolence, reduced physical activity and work-related productivity. ${ }^{2}$ Allergic rhinitis may be seasonal, also referred to as Hay fever, or perennial. ${ }^{3}$ Seasonal form usually occurs due to allergy to pollens. Perennial form is caused by urban air pollutants, such as smoke from automobiles, factories and other sources. Other causes are dust mites, animal dander and mould spores. 4,5 Strong fragrances are known to produce substantial levels of indoor air pollutants such as volatile organic products, ${ }^{6}$ which may cause rhinitis and airway irritation. ${ }^{7}$ Allergic rhinitis causes disturbance in the daily life of the person as well as reduction in productivity at work.8,9 A study estimated

Department of Surgery, Aga Khan University Hospital, Karachi, Pakistan.

Correspondence: Moghira Iqbaluddin Siddiqui. Email:moghira.siddiqui@aku.edu that the total direct and indirect expenditure made over allergic rhinitis was $\$ 5.3$ billion per year. ${ }^{10} \mathrm{An}$ analysis performed in 2011, determined that patients with allergic rhinitis had three additional office visits, $\$ 1,500$ more in incremental healthcare cost and had nine more prescriptions filled as compared to those without allergic rhinitis. ${ }^{11}$

The symptoms of allergic rhinitis are often ignored by the patients as well as physicians, and individuals who are affected with this condition usually do not report their problem and do not seek proper and effective treatment. ${ }^{12}$ Multiple studies have been conducted to see the prevalence of allergic rhinitis in different regions. The prevalence of allergic rhinitis has increased across the world. ${ }^{13}$ In United States, prevalence of allergic rhinitis ranges from $3 \%$ to $19 \%$ with 30 to 60 million people affected every year. Eighty percent of the cases of allergic rhinitis are younger than 20 years of age. ${ }^{14} \mathrm{~A}$ study conducted in 2012 showed that $9 \%$ of children below the age of 18 and $7.5 \%$ of adults reported allergic rhinitis in the past 12 months. ${ }^{15}$ The European Community Respiratory Health survey recorded a prevalence of allergic rhinitis in adults around 10 to $41 \% .16$ There may be a variation in the prevalence of allergic rhinitis within and among the countries as well. ${ }^{17}$

As the prevalence of allergic rhinitis is quite high, and due to its potential of causing significant impairment in quality of life and decrease in work productivity, many organisations such as American Lung Association,18 Canadian Centre for Occupational Health and Safety (CCOHS), ${ }^{19}$ Americans with Disabilities Act (ADA), Job Accommodation Network (JAN) and U.S. Department of Labour (DOL) ${ }^{20}$ have emphasised, formulated and adopted different policies for hospitals, public places and work places. Some of these emphasise on smoke and fragrance free workplace in order to reduce triggering of the symptoms of allergic rhinitis. Literature shows that healthcare workers may have an increased risk of allergy. Occupational allergy has emerged as an important healthrelated issue. ${ }^{21}$ Potential allergens affecting this group includes latex, disinfectants, sterilants, pharmaceuticals, 
sensitising metals, aerosolised medications and cleaning products. $22-24$ Although worker's health and productivity is affected by occupational allergic diseases, their effects are usually underestimated and are not given much importance by patients themselves. Literature is scarce when it comes to estimate the prevalence of allergic rhinitis in healthcare facilities. We conducted this study with the primary objective of determining the frequency of allergic rhinitis among healthcare professionals at a tertiary healthcare centre and how it impacts their work.

\section{Patients and Methods}

A cross sectional study was conducted at a tertiary healthcare centre from January 2018 to April 2018 after seeking approval from the ethical review committee. All adult individuals who were involved in providing healthcare to the patients at our institute including doctors, nurses, technicians, lab workers and pharmacists were included. Sample size was calculated through Epi Info Version 7.2.2.16. Based on the literature, expected frequency of $7 \%$ and $5 \%$ level of significance, the minimum sample size calculated was 100 . By adjusting for $10 \%$ nonresponse at least 110 study participants were required to enrol in the study. We approached 167 individuals and all of them participated in the study and since all fell in the inclusion criteria we included all 167 participants. All those who were not able to read or did not give consent were excluded. After taking informed consent all the participants were asked to fill a questionnaire consisting of two parts. The questionnaire was designed in English and was filled by the participants themselves with the help of a trained resident (medical doctor). First part of the questionnaire comprised "Score for allergic rhinitis (SFAR)" assessment form. SFAR assessment form is a quantitative tool which has a score from 0 to 16 . It is a validated tool to estimate prevalence of allergic rhinitis. 25 Participants with score of 8 and above were considered as having allergic rhinitis 26 and were asked to fill the second part which comprised "Work productivity and activity impairment questionnaire (WPAI)" which was used to see the impact of allergic rhinitis on work. WPAI questionnaire is an instrument to measure impairments in both paid and unpaid work. ${ }^{27}$ It has been validated to quantify work impairments for many diseases including allergic rhinitis, asthma, Crohn's disease and inflammatory bowel syndrome.

Data was stored and analysed in SPSS version 25. Frequency with percentages was reported for the qualitative variables to describe the prevalence in the study population.

\section{Results}

A total of 167 healthcare workers were invited and all of them participated in the study. The mean age of participants was $29.0 \pm 5.9$ years. Majority of them were males $101(60.4 \%)$. Workwise $77(46 \%)$ of the total participants were technicians (laboratory, operating room and radiology), followed by 40 (24\%) nurses, 30 (18\%) doctors and 20 (12\%) pharmacists. Overall, 32(19.2\%) had allergic rhinitis (Table 1). Women had a 2.2 times higher burden of this condition than males $18(28.8 \%)$ verses $21(12.9 \%)$ respectively ( $p=0.011)$. Workwise the prevalence of allergic rhinitis was highest among doctors 10 (30\%), followed by nurses 8 (20\%), technicians $12(15.6 \%)$ and pharmacists $3(15 \%)$. However this workwise difference was not statistically significant. The most common symptom in the participants with allergic rhinitis was sneezing followed by itchy and watery eyes, runny or blocked nose (Table 2). Majority of them $21(68.8 \%)$ reported experiencing these symptoms during winters and having allergy to dust $24(75 \%)$, smoke $16(50 \%)$ and perfumes $8(25 \%)$. The associated severity of the symptoms on a Likert scale of 1 to 10 is reported in Table 3. Out of the 32 patients with established allergic rhinitis only 7 (21.9\%) reported no work loss. However, 13 (40.6\%) reported missing work in the past week due to allergic

Table-1: Prevalence of allergic rhinitis.

\begin{tabular}{llcc}
\hline Characteristic & Interviewed & n (\%) \\
\hline \multirow{2}{*}{ Age group } & $\leq 29$ & 108 & $24(22.2)$ \\
& $\geq 30$ & 59 & $8(13.6)$ \\
\multirow{4}{*}{ Gender } & All & 167 & $32(19.2)$ \\
& Male & 101 & $13(12.9)$ \\
Occupation & Female & 66 & $19(28.8)$ \\
& Doctor & 30 & $9(30.0)$ \\
& Nurse & 40 & $8(20.0)$ \\
& Technician & 77 & $12(15.6)$ \\
& Pharmacist & 20 & $3(15.0)$ \\
& Yes & 20 & - \\
& No & 147 & $32(21.8)$ \\
\hline
\end{tabular}

Allergic rhinitis was defined as score $\geq 8$ on SFAR*

Table-2: Common allergic symptoms among participants with allergic rhinitis $(n=32)$.

\begin{tabular}{lc}
\hline Symptom & $\mathbf{n}(\%)$ \\
\hline Sneezing & $31(96.9)$ \\
Watery and itchy eyes & $29(90.6)$ \\
Runny nose & $27(84.4)$ \\
Blocked nose & $26(81.2)$ \\
\hline
\end{tabular}


Table-3: Severity of sensitivity among those with allergic rhinitis $(n=32)$ on Likert scale (1-10).

\begin{tabular}{lc}
\hline & Mean \pm SD \\
\hline Sensitivity to dust & $7.0 \pm 2.7$ \\
Sensitivity to smoke & $6.7 \pm 3.2$ \\
Sensitivity to fragrance & $4.4 \pm 3.2$ \\
\hline
\end{tabular}

* SFAR score for Allergic Rhinitis

issues, accounting for $4.3 \%$ of their working time. In addition $38.5 \%$ of the participant's regular daily activities were disturbed due to allergic rhinitis. Sixteen (50\%) of the participants relied on minimising exposure by moving away from the irritant. Only one quarter of the participants $8(25 \%)$ with allergic rhinitis sought medical advice. Majority of them were using over-the-counter oral antihistamine $22(68.8 \%)$ and topical nasal sprays $20(65.6 \%)$. There were $9(28.1 \%)$ individuals who were using topical vasoconstrictor nasal spray and one of them was using it on a daily basis. Majority of the allergic individuals $23(72 \%)$ believed that there should be an institutional policy for decreasing exposure to allergens at the workplace and $50 \%(16 / 32)$ wanted their workplace to be fragrance free.

\section{Conclusion}

Our study suggests a prevalence of allergic rhinitis in 19\% of healthcare workers. Female healthcare workers were 2.2 times more prone to this condition. Allergic rhinitis is a bothersome condition and has a negative impact on work productivity of healthcare workers. Implementing preventive measures and paying attention to work environment can help in controlling allergic rhinitis and its impact on work. It highlights the need for increasing awareness so that a pragmatic treatment can be offered for this condition. It provides a basis for institutional policies for a healthier air in our institutions.

\section{Disclaimer: None. \\ Conflict of Interest: None. \\ Funding Sources: None.}

\section{References}

1. Bousquet J, Khaltaev N, Cruz AA, Denburg J, Fokkens W, Togias A et al. Allergic Rhinitis and its Impact on Asthma (ARIA) 2008 update (in collaboration with the World Health Organization, GA(2)LEN and AllerGen). Allergy. 2008; 63:8-160.

2. Mahboub B, Al-Hammadi S, Prakash VP, Sulaiman N, Blaiss MS, AI Redha $A$, et al. Prevalence and triggers of allergic rhinitis in the United Arab Emirates. World Allergy Organ J. 2014; 7:19.

3. Kaliner M. EgglestonPA. Rhinitis and asthma. JAMA. 1987; 258:285173.
4. Ishizaki T, Koizumi K, Ikemori R, Ishiyama Y, Kushibiki E. Studies of prevalence of Japanese cedar pollinosis among the residents in a densely cultivated area. Ann Allergy. 1987; 58:265-70.

5. Williams PB, Buhr MP, Weber RW, Volz MA, Koepke JW, Selner JC. Latex allergen in respirable particulate air pollution. J Allergy Clin Immunol. 1995; 95:88-95.

6. Singer BC, Coleman BK, Destaillats $\mathrm{H}$, Hodgson AT, Lunden MM, Weschler $\mathrm{CJ}$, et al. Indoor secondary pollutants from cleaning product and air freshener use in the presence of ozone. Atmospheric Envir. 2006; 40:6696-710.

7. Larsson ML, Frisk M, Hallström J, Kiviloog J, Lundbäck B. Environmental tobacco smoke exposure during childhood is associated with increased prevalence of asthma in adults. Chest. 2001; 120:711-7.

8. Blaiss MS. Quality of life in allergic rhinitis. Ann Allergy Asthma Immunol. 1999; 83:449-54.

9. Thompson AK, Juniper E, Meltzer EO. Quality of life in patients with allergic rhinitis. Ann Allergy Asthma Immunol. 2000; 85:338-44.

10. Ray NF, Baraniuk JN, Thamer M, Rinehart CS, Gergen PJ, Kaliner M, et al. Direct expenditures for the treatment of allergic rhinoconjunctivitis in 1996, including the contributions of related airway illnesses. J Allergy Clin Immunol. 1999; 103:401-7.

11. Bhattacharyya N. Incremental healthcare utilisation and expenditures for allergic rhinitis in the United States. Laryngoscope. $2011 ; 121: 1830-3$.

12. Greiner AN, Hellings PW, Rotiroti G, Scadding GK. Allergic rhinitis. Lancet. 2011; 378:2112-22.

13. Björkstén B, Clayton T, Ellwood P, Stewart A, Strachan D; ISAAC Phase III Study Group. Worldwide time trends for symptoms of rhinitis and conjunctivitis: Phase III of the International Study of Asthma and Allergies in Childhood. Pediatr Allergy Immunol. 2008; 19:110-24.

14. Pawankar R, Canonica G, Holgate S, Lockey R. World Allergy Organisation (WAO) white book on allergy. Wisconsin:World Allergy Organisation, 2011.

15. Bloom B, Dey AN, Freeman G. Summary health statistics for US children; National health interview survey, 2005. 2009.

16. Heinrich J, Richter K, Frye C, Meyer I, Wölke G, Wjst M, et al. European Community Respiratory Health Survey in Adults (ECRHS). Pneumologie. 2002; 56:297-303.

17. Romano-Zelekha O, Graif Y, Garty BZ, Livne I, Green MS, Shohat T. Trends in the prevalence of asthma symptoms and allergic diseases in Israeli adolescents: results from a national survey 2003 and comparison with 1997. J Asthma. 2007; 44:365-9.

18. Lung.org. American Lung Association [Online] [Cited 2018 October 16]. Available from: URL: https://www.lung.org/support-andcommunity/corporate-wellness/.

19. Ccohs.ca. Healthy Work places. [Online] [Cited 2018 October 16]. Available from: URL: https://www.ccohs.ca/healthyworkplaces/.

20. Dol.gov. [Online] [Cited 2017 November 14]. Available from: http://www.dol.gov/general/topic/disability/ada. PAGE NOT FOUND

21. Sato K, Kusaka Y, Suganuma N, Nagasawa S, Deguchi Y. Occupational allergy in medical doctors. J Occup Health. 2004; 46:165-70.

22. Delclos GL, Gimeno D, Arif AA, Burau KD, Lusk C, Stock T, et al. Occupational risk factors and asthma among health care professionals. Am J Respir Crit Care Med. 2007; 175:667-75.

23. Mapp CE, Boschetto $P$, Maestrelli $P$, Fabbri LM. Occupational asthma. Am J Respir Crit Care Med. 2005; 172:280-305.

24. Pechter E, Davis LK, Tumpowsky C, Flattery J, Harrison R, Reinisch $\mathrm{F}$, et al. Work-related asthma among health care workers: Surveillance data from California, Massachusetts, Michigan, and New Jersey, 1993-1997. Am J Ind Med. 2005; 47:265- 75.

25. Ologe FE, Adebola SO, Dunmade AD, Adeniji KA, Oyejola BA. Symptom score for allergic rhinitis. Otolaryngol Head Neck Surg. 2013; 148:557-63. 
26. Annesi-Maesano I, Didier A, Klossek M, Chanal I, Moreau D, Bousquet J. The score for allergic rhinitis (SFAR): a simple and valid assessment method in population studies. Allergy. 2002; 57:107-14.

27. Reilly MC, Zbrozek AS, Dukes EM. The validity and reproducibility of a work productivity and activity impairment instrument. Pharmacoeconomics. 1993; 4:353-65.

28. Keith PK, Desrosiers M, Laister T, Schellenberg RR, Waserman S. The burden of allergic rhinitis (AR) in Canada: perspectives of physicians and patients. Allergy Asthma Clin Immunol. 2012; 8:7.

29. Bauchau V, Durham S. Prevalence and rate of diagnosis of allergic rhinitis in Europe. Eur Respir J. 2004; 24:758-64.
30. Abdulrahman $\mathrm{H}$, Hadi U, Tarraf H, Gharagozlou M, Kamel M, Soliman A, et al. Nasal allergies in the Middle Eastern population: results from the "Allergies in Middle East Survey". Am J Rhinol Allergy. 2012; 26:S3-23.

31. Bilge U, Unluoglu I, Son N, Keskin A, Korkut $Y$, Unalacak M. Occupational allergic diseases in kitchen and health care workers: an underestimated health issue. Biomed Res Int. 2013; 2013:285420.

32. Blanc PD, Trupin L, Eisner M, Earnest G, Katz PP, Israel L, et al. The work impact of asthma and rhinitis: findings from a populationbased survey. J Clin epidemiology. 2001; 54:610-8. 